\title{
Overshadowing and stimulus intensity
}

\author{
N. J. MACKINTOSH \\ University of Sussex, Brighton, England BNI $9 Q G$
}

\begin{abstract}
Two experiments on conditioned suppression in rats examined overshadowing between visual and auditory components of a compound conditioned stimulus. In the first experiment, when one component was markedly more salient than the other, the more salient overshadowed the less salient, but the latter, although acquiring significant associative strength, did not overshadow the former. When the two components were of approximately equal salience, each overshadowed the other. In the second experiment, reciprocal overshadowing was again observed between two equally salient stimuli, but only when their absolute intensities were relatively low. The failure to cbserve reciprocal overshadowing under all conditions raises problems for those theories of stimulus selection which assume that stimuli compete for some strictly limited resource. It was suggested, instead, that overshadowing might occur when animals fail to learn to attend to, or actually learn to ignore, stimuli that are not uniquely successful predictors of reinforcement.
\end{abstract}

Pavlov (1927, p. 141) used the term "overshadowing" to describe the observation that conditioning to a relatively weak stimulus might be severely attenuated if it was always presented in conjunction with a more intense stimulus. The stronger or more salient component of a compound conditioned stimulus (CS) was said to overshadow conditioning to the weaker or less salient component. This finding has usually been attributed to some sort of competition between stimuli. According to theories of selective attention (Sutherland \& Mackintosh, 1971), conditioning requires that the subject attend to the $\mathrm{CS}$, and there is an inverse relationship between the probabilities or strengths of attention to different stimuli. According to Rescorla and Wagner (1972), there is a limit to the associative strength conditionable by a given reinforcer, and this fixed total must be shared between all CSs present on any trial. Both theories provide a straightforward account of overshadowing; if one component of a compound CS is more salient than the other, it will capture the major share of attention or associative strength, and will thus interfere with conditioning to the other.

Both theories further predict that, although the magnitude of overshadowing effects will depend on the relative intensities of the two components, overshadowing should in general be a reciprocal affair, with each element of a compound CS to some extent detracting from conditioning to the other. If a fixed amount of attention or associative strength is to be distributed among the elements of a

This research was supported by grants from the National Research Council of Canada and the United Kingdom Science Research Council. I am very grateful to A. Dickınson and G. Hall for their comments on an earlier draft. compound $\mathrm{CS}$, any conditioning accruing to one component will presumably be at the expense of conditioning to the others. There is, indeed, evidence that overshadowing increases either with an increase in the intensity of the overshadowing component (e.g., Miles \& Jenkins, 1973) or with a decrease in the intensity of the overshadowed component (e.g., Kamin, 1969), but there is very little evidence that each component detracts from conditioning to the other (Mackintosh, 1975a). There was little sign that the weaker element overshadowed the stronger in Miles and Jenkins' and Kamin's experiments; nor is there much evidence of reciprocal overshadowing by two equally salient elements of a compound (e.g., Schnur, 1971; Sutherland \& Andelman, 1967).

The two experiments reported here were designed to provide more systematic evidence on this question than is at present available. Both experiments studied conditioned suppression in rats with visual and auditory CSs. In the first, the visual CS was a light of fixed intensity and the auditory CS was white noise, varying in intensity for different groups. The assumption was that the most intense noise would reliably overshadow the light, while the least intense noise would itself be reliably overshadowed by the light. It would then be possible to ask whether, at these two extremes, the less salient component would significantly detract from conditioning to the more salient. Subjects conditioned with intermediate intensities of the noise would provide data on reciprocal overshadowing when the light and the noise were of approximately equal salience. A second experiment investigated whether reciprocal overshadowing was affected by the absolute intensity of two equally salient stimuli. 


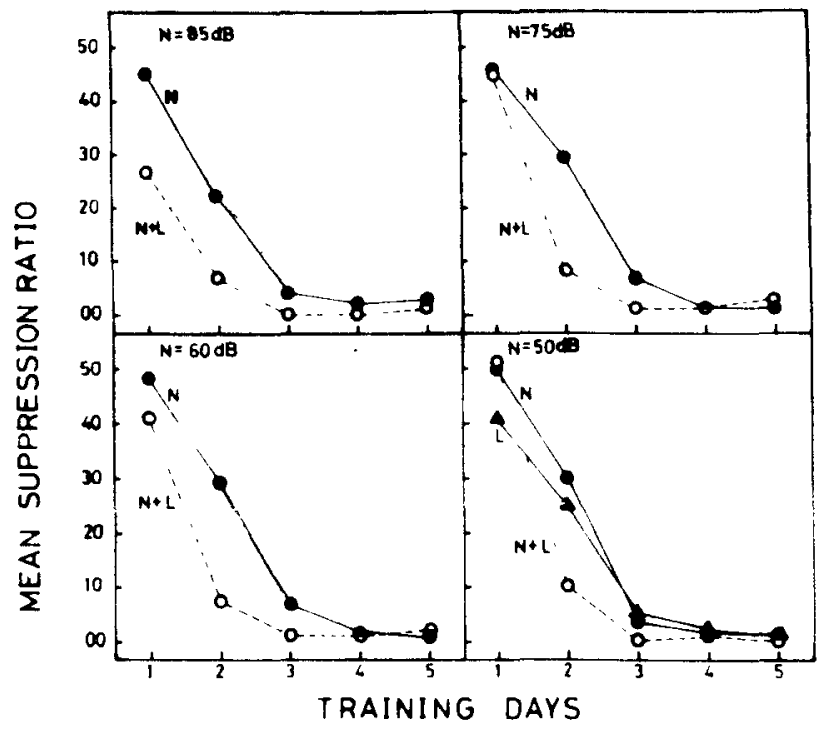

Figure 1. Experiment I: Acquisition of conditioned suppression.

\section{EXPERIMENT I}

\section{Method}

Subjects and apparatus. The subjects were 72 male hooded rats, obtained from Charles River Laboratories, St. Constant, Quebec, and weighing $250-300 \mathrm{~g}$ on arrival in the laboratory. They were maintained at $80 \%$ of their ad lib weights for the duration of the experiment. The apparatus consisted of two Grason-Stadler single-lever rat chambers, each equipped with an overhead 40-W, 110-V strip light diffused through a white Perspex ceiling. The chambers were enclosed in soundattenuatıng shells, with automatic programming equipment located in an adjoining room. They were permanently illuminated with a $75-\mathrm{W}$ houselight mounted behind the front wall, and exhaust fans provided a permanent masking noise. The light CS was produced by switching on the overhead light; the auditory CSs were produced by a Grason-Stadler white noise generator; the intensity of the norse, measured at floor level in the center of the chamber, was $50,60,75$, or $85 \mathrm{~dB}$ (re $20 \mu \mathrm{N} / \mathrm{m}^{2}$ ).

Procedure. Throughout the experiment, all sessions lasted $1 \mathrm{~h}$. In the first session, free food (45-mg Noyes pellets) was delivered on a valable interval (VI) 1 -min schedule. In the next 2 sessions, leverpressing was reinforced on a VI schedule which was gradually lengthened to $1 \mathrm{~m}$. Subjects then recelved 6 further sessions of VI 1 -min reinforcement followed by 2 sessions of pretesting, 10 conditioning sessions, and 5 test sessions, during all of which the VI 1-min schedule of reinforcement remained in effect.

In the first pretest session, subjects recelved two nonreinforced trals to the light, and in the second, two nonreinforced trials to the noise. The duration of the stımuli was $2 \mathrm{~min}$, and the trials occurred 25 and 50 min after the beginning of the session. Each conditioning session also contained two trials, occurring at the same points, with each trial consisting of a 2 -min CS terminating with a $0.5-\mathrm{sec}, 1.0-\mathrm{mA}$ scrambled shock delivered to the grid floor. There were four nonreinforced trials in each test session, occurring $13,25,37$, and $49 \mathrm{~min}$ after the start of the session. All subjects were tested with both the light (L) and the noise (N). The stimuli were presented in the sequence LNNL and NLLN on alternate days, with half the subjects in each group starting with one sequence, and half with the other.

There were nine experimental groups, with eight subjects per group. Four groups were conditioned to the noise alone, one group at each intensity: they are referred to as Groups $\mathrm{N}(85), \mathrm{N}(75), \mathrm{N}(60)$, and $\mathrm{N}(50)$. Four groups were conditioned to the noise-light compound, and are referred to as $\mathrm{N}+\mathrm{L}(85), \mathrm{N}+\mathrm{L}(75), \mathrm{N}+\mathrm{L}(60)$, and $\mathrm{N}+\mathrm{L}(50)$. The ninth group was conditioned to the light alone (Group $L$ ). The eight groups exposed to the noise on conditioning trials received pretest and test trials with the noise at the same intensity as in conditioning. Group L was pretested and tested with the $50-\mathrm{dB}$ noise.

\section{Results and Discussion}

Conditioning was measured by the calculation of suppression ratios according to the formula $a /(a+b)$, where $a=$ the number of responses during the CS, and $b=$ the number of responses during a 2-min period preceding the CS. Responses were cumulated over the two trials of each conditioning session, and separately over the two light trials and two noise trials of each test session, thus providing a single daily suppression ratio for each subject to each stimulus.

The acquisition of suppression over Days 1-5 of conditioning is shown in Figure 1. Each of the four panels shows the data for one pair of groups, $\mathrm{N}$ and $\mathrm{N}+\mathrm{L}$, conditioned to one of the four intensities of noise. The data for Group $L$ are shown in the fourth panel along with those of Groups $N(50)$ and $N+L(50)$. As can be seen, suppression was essentially complete after 3 days of conditioning; it remained complete, and the data for the final 5 days of conditioning are not illustrated, and were not subject to statistical analysis. Conditioning clearly proceeded more rapidly in compound groups $(\mathrm{N}+\mathrm{L})$ than in component groups $(\mathrm{N}$ or $\mathrm{L})$, but there is little suggestion that the difference between Groups $\mathrm{N}+\mathrm{L}$ and $\mathrm{N}$ varied with the intensity of the noise. An analysis of variance on the scores of the four $\mathrm{N}$ and four $\mathrm{N}+\mathrm{L}$ groups showed that the presence of the light significantly facilitated conditioning, $F(1,56)=22.09, p<.001$, but there was no significant effect of noise intensity, $F(3,56)=1.73, p>.10$, or any interaction between the two effects $(F<1)$. The effect of days was significant, $F(4,224)=307.33, p<.001$, as was the interaction between intensity and days, $F(12,224)$ $=1.91, \mathrm{p}<.05$. This significant interaction suggests that the more intense values of the noise produced somewhat greater suppression on Days 1 and 2.

The test results are shown in Table 1 and Figures

Table 1

Mean Suppression Ratios to Noise and Light Over All Test Trials in Experiment $I$

\begin{tabular}{ccccc}
\hline & \multicolumn{2}{c}{ Group N + L } & \multicolumn{2}{c}{ Group N } \\
$\begin{array}{c}\text { Noise } \\
\text { Intensity }\end{array}$ & $\begin{array}{c}\text { Sight } \\
\text { Score }\end{array}$ & $\begin{array}{c}\text { Noise } \\
\text { Score }\end{array}$ & $\begin{array}{c}\text { Light } \\
\text { Score }\end{array}$ & $\begin{array}{c}\text { Noise } \\
\text { Score }\end{array}$ \\
\hline 85 & .39 & .18 & .45 & .21 \\
75 & .36 & .30 & .44 & .16 \\
60 & .29 & .41 & .42 & .22 \\
50 & .18 & .38 & .45 & .22 \\
Group L & .14 & .49 & & \\
\hline
\end{tabular}




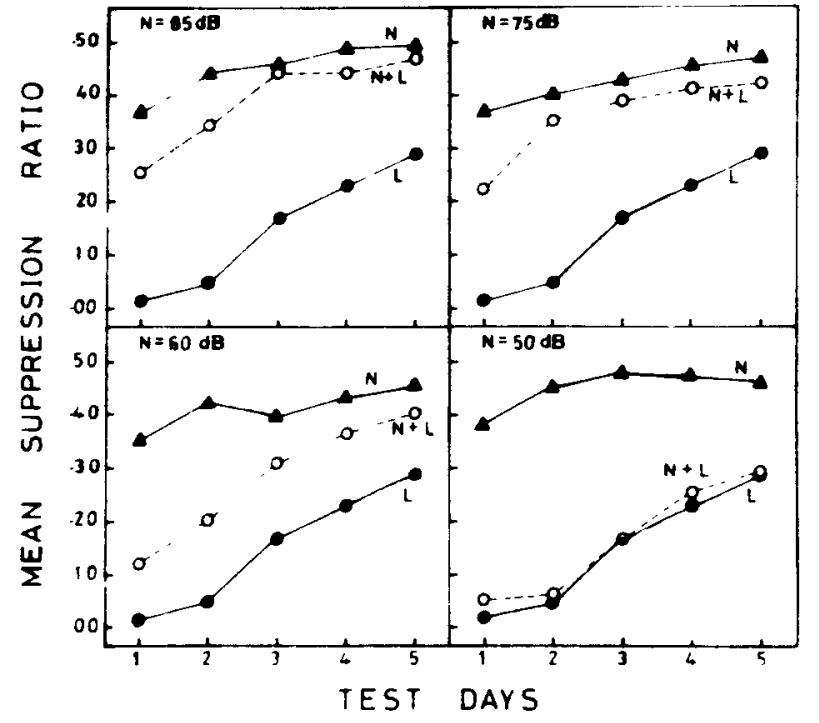

Figure 2. Experiment 1: Results of test trials to the light.

2 and 3. Table 1 gives the mean suppression ratio over all test trials for each group to each stimulus. The data for the $\mathrm{N}+\mathrm{L}$ groups show an orderly increase in supprecsion to the light as noise intensity decreases, accompanied by a relatively orderly decrease in suppression to the noise. The $\mathbf{N}$ groups, never reinforced in the presence of the light, naturally show comparable and low levels of suppression to the light and substantially more suppression to the noise. Perhaps rather more surprisingly, there is no suggestion of a decline in suppression to the noise as intensity decreases. This suggests that all groups must have reached the same high asymptote of conditioning by the end of training.

Figures 2 and 3 give the daily suppression ratios for each group, with the data for trials 10 the light in Figure 2, and those for trials to the noise in Figure 3. In Figure 2, the scores of Group L are repeated in each of the four panels in order to provide a visual impression of the magnitude of the overshadowing effect of the noise at each intensity. Overshadowing of the light by the noise is seen as a difference between Group L and each Group $\mathrm{N}+\mathrm{L}$. Both Table 1 and Figure 2 suggest that this overshadowing effect decreases as the intensity of the noise decreases, finally vanishing when the intensity is $50 \mathrm{~dB}$. Conversely, the difference between the scores for Groups $\mathrm{N}$ and $\mathrm{N}+\mathrm{L}$ in each panel is a measure of the amount of conditioning accruing to the light in each compound group. The figure suggests that this decreases as the intensity of the noise increases, but does not vanish even in Group N + L(85).

Statistical analysis supported these suggestions. Since there was only a single Group $L$ in the experiment, it was not possible to perform a iactorial analysis comparing Groups $\mathrm{N}+\mathrm{L}$ and $\mathrm{L}$ at each intensity; instead, the four $\mathrm{N}+\mathrm{L}$ groups and the one $L$ group were treated as five unrelated groups for an overall analysis of variance, which also included days as a second factor. In this and all further analyses of variance, the main effect of days was significant, but since this is of no great consequence it will not be further mentioned. The difference between the five groups was significant, $\mathrm{F}(4,35)=12.52, \mathrm{p}<.001$, but the interaction with days was not significant, $F(16,140)=1.37$, $p>$.10. Newman-Keuls tests showed that Group L differed from each of Groups $N+L(60)$, $\mathrm{N}+\mathrm{L}(75)$, and $\mathrm{N}+\mathrm{L}(85)$ at the .01 level, but did not differ from Group $N+L(50)$.

A second analysis was performed on Groups $\mathrm{N}$ and $\mathrm{N}+\mathrm{L}$ over the four intensities. There was a significant difference between the $\mathrm{N}$ and $\mathrm{N}+\mathrm{L}$ groups, $F(1,56)=13.57, p<.001$, a significant main effect of intensity, $F(3,56)=16.90, p<.001$, and a significant interaction between the two, $\mathrm{F}(3,56)=18.41, \mathrm{p}<.001$. There were also interactions between intensity and days, $F(12,224)$ $=12.66, \mathrm{p}<.001$, and between $\mathrm{N}$ vs. $\mathrm{N}+\mathrm{L}$, intensity, and days, $\mathrm{F}(12,224)=3.38, \mathrm{p}<.001$. In spite of the interaction between intensity and $\mathrm{N}$ vs. $\mathrm{N}+\mathrm{L}$, a subsidiary analysis comparing Groups $N(85)$ and $N+L(85)$ revealed a significant difference between the two groups even at this extreme intensity, $\mathrm{F}(1,14)=10.25, \mathrm{p}<.01$.

The results of test trials to the noise are shown in Figure 3. Here the data for Group L are shown only in the fourth panel, since the group was tested with the $50-\mathrm{dB}$ noise. In this figure, the difference between Groups $\mathrm{N}$ and $\mathrm{N}+\mathrm{L}$ measures overshadowing of the noise by the presence of the light; the impression gained from the figure is that

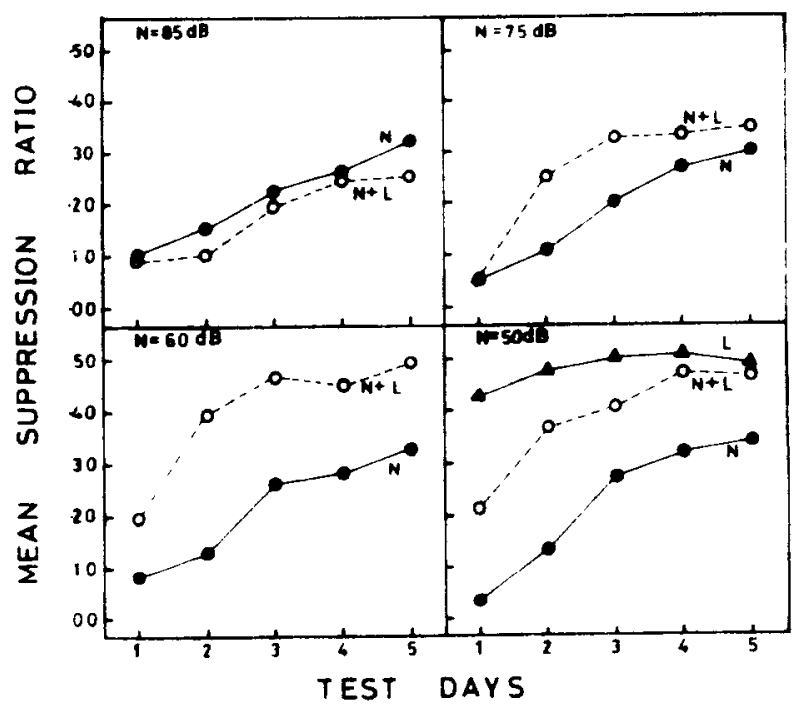

Figure 3. Experiment I: Results of test trials to the noise. 
this overshadowing effect declined as the intensity of the noise increased, completely vanishing in Group $N+L(85)$. The difference between Group $N+L(50)$ and $L$ is a measure of the amount of conditioning accruing to the noise in the compound group even at the lowest intensity of noise.

An analysis of variance comparing Groups $\mathrm{N}$ and $\mathrm{N}+\mathrm{L}$ at each intensity revealed a significant effect of the presence of the light, $F(1,56)=11.29$, $\mathrm{p}<.01$, a significant effect of the intensity of the noise, $F(3,56)=5.95, p<.01$, and a significant interaction between these two effects, $F(3,56)=$ $2.92, \mathrm{p}<.05$. No interaction with days was significant. Subsidiary analyses showed that Group N was more suppressed than Group $\mathrm{N}+\mathrm{L}$ at the three lowest intensities of the noise: at $50 \mathrm{~dB}, \mathrm{~F}(1,14)=$ $13.12, \mathrm{p}<.01$; at $60 \mathrm{~dB}, \mathrm{~F}=10.80, \mathrm{p}<.01$; and at $75 \mathrm{~dB}, F=4.67, \mathrm{~F}<.05$. But the reverse difference between Groups $\mathrm{N}(85)$ and $\mathrm{N}+\mathrm{L}(85)$ was not significant $(\mathrm{F}<1)$.

A second analysis compared Groups $\mathrm{N}+\mathrm{L}(50)$ and $L$. The difference between the two groups was significant, $F(1,14)=11.40, p<.01$, as was the interaction between groups and days, $F(4,56)=$ $4.56, \mathrm{p}<.01$.

\section{Discussion}

Although their detailed analysis has perhaps seemed unduly complex, the results of this experiment are in fact quite straightforward. Overshadowing was an orderly function of the relative intensities of the noise and light. Overshadowing of the light by the noise increased as the intensity of the noise increased, while overshadowing of the noise by the light increased as the intensity of the noise decreased. At the two intermediate intensities of the noise, there was clear evidence of reciprocal overshadowing, with the presence of the noise detracting from conditioning to the light and the presence of the light simultaneously detracting from conditioning to the noise. Groups $\mathrm{N}+\mathrm{L}(75)$ and $N+L(60)$ were less suppressed to the light than Group L, and less suppressed to the noise than Groups N(75) and N(60).

At the extreme intensities of the noise, however, although there was ample evidence that the more salient element overshadowed the less salient, there was no suggestion that the latter overshadowed the former. Thus, Group N + L(85) was less suppressed to the light than Group L, and Group N + L(50) was less suppressed to the noise than Group $N(50)$, but Group $N+L(85)$ was not less suppressed to the noise than Group $\mathrm{N}(85)$, and nor was Group $\mathrm{N}+\mathrm{L}(50)$ less suppressed to the light than Group L. Reciprocal overshadowing, therefore, was apparently confined to the intermediate intensities of the noise, where, perhaps, the noise and light were of approximately equal salience.

Why should the less salient element in the two extreme cases have apparently failed to overshadow the more salient? No such overshadowing would, of course, be expected if the less salient element had itself been so completely overshadowed by the more salient element that it acquired no associative strength. This, however, was clearly not the case. Although the light did not overshadow the 85- $\mathrm{dB}$ noise in Group $\mathrm{N}+\mathrm{L}(85)$, this was not because the light failed to acquire associative strength in this group [compare the difference between Groups $N+L(85)$ and $N(85)$ in suppression to the light]. Similarly, although the noise did not overshadow the light in Group $\mathrm{N}+\mathrm{L}(50)$, the comparison between that group and Group $\mathrm{L}$ in suppression to the noise shows that the $50-\mathrm{dB}$ noise was not completely overshadowed by the light.

A more plausible explanation of the absence of overshadowing of the more salient element by the less salient in these cases is that a floor effect has obscured a small but genuine difference between the relevant groups. It is clearly difficult to rule out such a possibility. Moreover, no theory of overshadowing would expect the effect here to be anything but small. Two points, however, are perhaps worth noting. First, subjects were tested over 5 days of extinction, to the point where no group had a suppression ratio below .25 . It is rather unlikely that a floor effect could have continued to obscure genuine differences in suppression at this point. Secondly, one might wonder why, if a floor effect has obscured a genuine difference between, say, Groups $\mathrm{N}+\mathrm{L}(85)$ and $\mathrm{N}(85)$ in suppression to the noise, the difference between the two groups in suppression to the light, which theoretically one would not expect to have been any larger, was not equally obscured by a ceiling effect. Since testing was conducted in extinction, floor effects should have progressively decreased, but ceiling effects progressively increased.

\section{EXPERIMENT II}

The least equivocal result of the first experiment is that, at the intermediate intensities of the noise, there was ample evidence of reciprocal overshadowing between two stimuli of, presumably, approximately equal salience. This conclusion differs from that suggested by the experiments mentioned in the introduction (e.g., Schnur, 1971). Experiment II, therefore, was designed to provide further evidence on the question, and specifically to see whether the absolute intensity of two equally salient stimuli would affect the extent to which they overshadowed each other. 


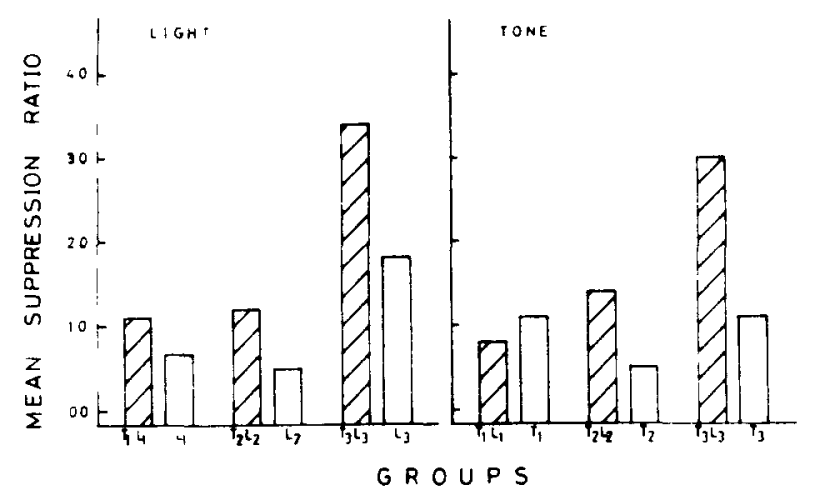

Figure 4. Experiment II: Group mean suppression ratios on the first test trial.

\footnotetext{
Method

Subjects and apparatus. The subjects were 96 female hooded rats from the colony maintained at the University of Sussex, weighing approximately $250 \mathrm{~g}$. They were maintained on a schedule of water deprivation which permitted access to water for $30 \mathrm{~min}$ each day immediately after each experimental session.

The apparatus, described in more detail elsewhere (Mackıntosh, 1975b), consisted of two boxes with transparent Perspex ceilings and grid floors. A $1-\mathrm{cm}$-diam hole in the front wall provided access to the tube of a water bottle, and licks at the tube were recorded by a drinkometer circuit. The CSs were a $\therefore, 800-\mathrm{Hz}$ tone from a speaker mounted in the center of the rear wall, and a light mounted $5 \mathrm{~cm}$ above the Perspex ceiling. There were three intensities of the tone: $T_{1}=96 \mathrm{~dB} ; T_{2}=$ $78 \mathrm{~dB} ; \mathrm{T}_{3}=60 \mathrm{~dB}$ (re $20 \mu \mathrm{N} / \mathrm{m}^{2}$ ), and three corresponding intensities of the light: $\mathrm{L}_{1}=25 \mathrm{~W}, 240 \mathrm{~V} ; \mathrm{L}_{2}=15 \mathrm{~W}$, $240 \mathrm{~V} ; \mathrm{L}_{3}=15 \mathrm{~W}, 240 \mathrm{~V}$, but with the chamber permanently Illuminated with a $24-\mathrm{V}$ houselight mounted in the rear wall above the speaker. For all other conditions, the chambers were completely dark except when the light CS was presented

Procedure. The experiment consisted of the following phases: Three prelımınary sessions, in which subjects were trained to lick at the water tube; one preexposure and five conditioning ,essions, during which the water bottles were removed; two lecovery sessions, in which the bottles were returned, but no stimuli were presented; and three test sessions, with one test irial in each session. Preliminary, recovery, and test sessions lasted $8 \mathrm{~m}$ in plus the time required for the subject to complete 200 hicks. The subject's 200th lick after being placed in the apparatus initiated a series of eight 1 -min periods, the first and ,econd of which served as pre-CS and CS periods during test sessions. In the preexposure session, which was $28 \mathrm{~min}$ long, there were six trials, two presentations each of the tone, the light, and the tone-light compound, at intensities appropriate or each group. The stmmuli were $1 \mathrm{~min}$ long, and the first Irial occurred $5 \mathrm{~min}$ after the start of the session, and subsequent trals at 4 -min intervals. The conditioning sessions were $20 \mathrm{~min}$ long, and there were four trials in each session, the first occurring after $5 \mathrm{~min}$ and subsequent trials at 4-min intervals. Each trial consisted of the presentation of a $\mathrm{I}$-min CS which terminated with the delivery of a $0.75-\mathrm{sec}, 0.4-\mathrm{mA}$ shock to the grid floor

There were four groups for each of the three intensitıes of the cone and light, one trained and tested with the tone, one trained and tested with the light, and two trained with the tone-light compound, of which one was tested with the tone and the other with the light. There were thus 12 groups with eight subjects per group, referred to as Groups $T_{1}, L_{1}$, and $T_{1} L_{1}$, etc. In this experiment, it should be noted, unlike Experiment $I$, ubjects were tested with only' a single stimulus.
}

\section{Results and Discussion}

The intensity of the shock chosen for the UCS was sufficient to ensure good conditioning, but not so strong as to produce complete suppression in all subjects, thus obscuring by floor effects any differences between groups. The mean suppression ratios on the first test trial are shown for each group in Figure 4, and averaged over all three test trials in Figure 5. Although the level of suppression shown by all groups is naturally somewhat greater on Trial 1 than when averaged over all three test trials, the pattern of differences between the various groups is much the same in both figures. The level of suppression tends to decline as the intensity of the stimuli decreases, but the decline is larger in groups conditioned to the tone-light compound than in those conditıoned to the tone or light alone. Overshadowing, therefore, which is measured by the difference between component and compound groups, occurs clearly only in groups conditioned to the least intense stimuli $\left(\mathrm{T}_{3}\right.$ and $\left.\mathrm{L}_{3}\right)$, although there is certainly a consistent suggestion of an effect at the intermediate intensity. Finally, there is no systematic difference between suppression to the light and suppression to the tone at any intensity.

An overall analysis on the Trial 1 scores showed a significant difference between compound and component groups, $\mathrm{F}(1,84)=11.00, \mathrm{p}<.01$, a main effect of intensity, $F(2,84)=12.88, p<.001$, and a significant interaction, $F(2,84)=3.18$, $p<.05$. The modality of the test stımulus (tone or light) had no effect, and entered into no interaction $(F<1)$. Separate analyses at each intensity showed that only at the lowest intensity was the difference between compound and component groups significant. At $\mathrm{T}_{1}$ and $\mathrm{L}_{1}, \mathrm{~F}<1$; at $\mathrm{T}_{2}$ and $\mathrm{L}_{2}, \mathrm{~F}(1,28)=2.52, \mathrm{p}>.10 ;$ at $\mathrm{T}_{3}$ and $\mathrm{L}_{3}$, $F=18.61, p<.001$.

An analysis on the scores averaged over all three test trials gave relatively similar results. Modality of test stimulus had no effect $(F<1)$, but there were significant main effects of compound vs. component

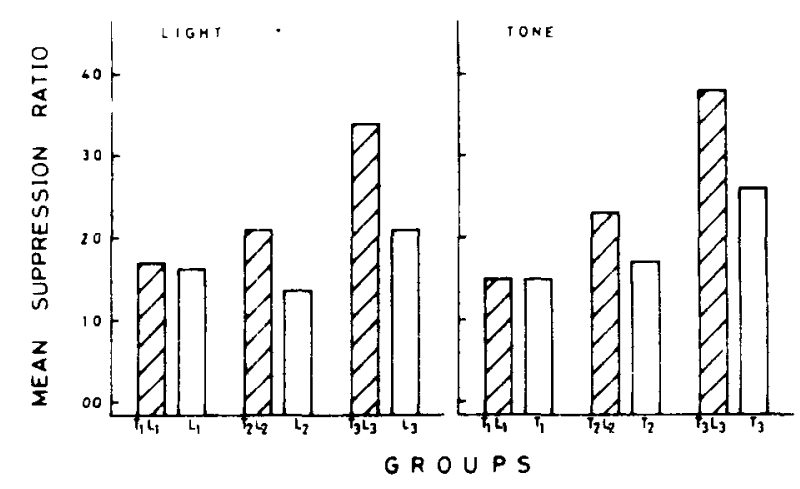

Figure 5. Experiment II: Group mean suppression ratios averaged over all test trials. 
groups, $F(1,84)=7.82, p<.01$, and of intensity, $F(2,84)=11.69, p<.001$; the interaction, however, was not significant, $F(2,84)=1.97, p>.10$. Again, however, separate analyses at each intensity revealed a significant overshadowing effect only at the lowest intensity, although now the difference approached significance at the intermediate intensity. At $T_{1}$ and $L_{1}, F<1 ;$ at $T_{2}$ and $L_{2}$, $\mathrm{F}(1,28)=2.98, .10>\mathrm{p}>.05$; at $\mathrm{T}_{3}$ and $\mathrm{L}_{3}$, $\mathrm{F}=9.83, \mathrm{p}<.01$.

Since the test scores to the tone and light did not differ at any intensity, in either compound or component groups, one may conclude that these stimuli were reasonably well matched for salience at each level (one cannot, of course, match for physical intensity across modalities, but salience is a behavioral measure). These results therefore confirm that equally salient components of a compound CS will reciprocally overshadow each other, but only if their absolute intensities are not too high. The absence of any overshadowing effect in Group $T_{1} L_{1}$ cannot reasonably be attributed to a floor effect. On Trial 1, it is true, suppression was relatively strong in all groups at this intensity, but over all three test trials, no group's suppression ratio was below .15. As can be seen from the Trial 1 data, this is very far from the maximum level of suppression conditionable by the present UCS.

A final possibility which should, perhaps, be considered is how far the scores shown in Figures 4 and 5 might reflect unconditioned suppression, especially to the more intense tones and lights. Since both preexposure and conditioning were conducted of 1 the baseline, there are no data from this phase of the experiment which would provide any measure of unconditioned suppression. Relevant data are, however, available from a pilot experiment, in which six groups, with either three or four rats per group, received preexposure and conditioning trials, exactly as in the main experiment, to one of the six tones and lights. All subjects then received two nonreinforced test trials to the tone or light used as their CS, followed by two test trials to the other, untrained, stimulus of the same intensity. Thus one group was conditioned to $T_{1}$, then tested first with $T_{1}$, and finally with $L_{1}$. For five of the six groups, the mean suppression ratios on the first test trial to the untrained stimulus ranged from .39 to .49 , indicating relatively little unconditioned suppression. The sixth group, trained with $\mathrm{T}_{2}$, had a suppression ratio of .31 when tested with $\mathrm{L}_{2}$. On the second test trial, no group had a suppression ratio below $\mathbf{. 4 5}$.

\section{GENERAL DISCUSSION}

The results of the present two experiments may serve to bring some order into the hitherto rather fragmentary evidence on the effects of salience or intensity on overshadowing. First, Experiment I confirmed what had already been established by other experiments (e.g., Kamin, 1969; Miles \& Jenkins, 1973), that the degree of overshadowing increases both with an increase in the intensity of the overshadowing element of a compound CS and with a decrease in the intensity of the overshadowed element. Secondly, the two experiments provided clear evidence that each element of a compound CS might overshadow the other. Miles and Jenkins (1973) presented data for one of the conditions of their experiment which indicated some reciprocal overshadowing, but, rather surprisingly, there has been no other published report of such a reciprocal effect. Finally, both experiments suggested that there might be some limit to the range of conditions under which reciprocal overshadowing can be expected. Experiment I suggested that two equally salient stimuli might overshadow each other, but that where two stimuli differed markedly in salience, the more salient might overshadow the less salient without the latter overshadowing the former. Experiment II suggested that even when the two elements of a compound CS were of approximately equal salience, overshadowing might not occur when they were both very intense.

Much of this evidence is entirely consistent with existing accounts of overshadowing (Rescorla \& Wagner, 1972; Sutherland \& Mackintosh, 1971). Both of these theories predict that the degree of overshadowing should vary with the relative salience of each element, and both predict reciprocal overshadowing by each element of a compound CS. The only problems for these theories are raised by the failure to find reciprocal overshadowing under all conditions. Of the two exceptions, that observed in Experiment I is the less serious. Both theories predict, for example, that overshadowing of the light by the noise in that experiment should have decreased as the intensity of the noise decreased. One might argue, then, that in the extreme case the experiment has simply failed to detect a difference which one would anyway have expected to be small. The results of Experiment II, however, are less easily dismissed. There is no discernible reason why either theory should lead one to expect any decline in reciprocal overshadowing as the intensity of the stimuli increases. Rescorla and Wagner (1972) make quite explicit statements about the distributions of associative strength between two elements, A and B, of a compound CS. At asymptote, $\mathrm{A}$ will have acquired a proportion, 
of the total associative strength conditionable by the reinforcer, and $B$ will have acquired the proportion

$$
\frac{\alpha_{\mathrm{B}}}{\alpha_{\mathrm{A}}+\alpha_{\mathrm{B}}}
$$

where $\alpha_{\mathrm{A}}$ and $\alpha_{\mathrm{B}}$ are parameters, lying within the unit interval, representing the salience or intensity of $A$ and $\mathrm{B}$. If $\alpha_{\mathrm{A}}=\alpha_{\mathrm{B}}$, then each stimulus will, at asymptote, acquire half the available associative strength, regardless of the absolute values of $\alpha_{\mathrm{A}}$ and $\alpha_{\mathrm{B}}$. At asymptote, therefore, reciprocal overshadowing should be unaffected by the absolute intensities of two equally salient stimuli. Since $\alpha$ is a learning-rate parameter, determining rate of approach to asymptote, conditioning will proceed more slowly with less intense stimuli. It is probable, therefore, that subjects conditioned to the most intense stimuli in Experiment II would have approached closer to asymptote than those conditioned to the least intense stimuli (indeed, the model as it stands has no other way of explaining why Group $T_{3} L_{3}$ was less suppressed on test trials than Group $\left.T_{1} L_{1}\right)$. Since the model predicts that interactions between the elements of a compound CS will increase as conditioning approaches asymptote, one would expect overshadowing to have increased rather than decreased as the intensity of the stimuli increased.

Although the discrepancy between data and theory is confined to only certain aspects of the data, it may be worth considering an alternative account of overshadowing which does not necessarily predict reciprocal overshadowing by each element of a compound CS (Mackintosh, 1975a). According to this analysis, overshadowing occurs because animals learn to ignore stimuli that predict the outcoine of a trial less well than other available stimuli, or fail to increase attention to stimuli. that are not the most reliable predictor of that outcome. Formally, the account follows Rescorla and Wagner's in assuming that the rate of conditioning to a stimulus, $\mathbf{A}$, is determined, inter alia, by the value of a learning-rate parameter, $\alpha_{A}$, whose initial value is set by the salience of $A$; unlike Rescorla and Wagner's model, however, the theory specifically assumes that $\alpha_{\mathrm{A}}$ may change with experience. It is assumed that $\alpha_{\mathrm{A}}$ increases if $\mathrm{A}$ predicts the outcome of a trial better than all other available stimuli, and decreases if $\mathbf{A}$ is a less valid predictor of the outcome of the trial. Formally, changes in $\alpha_{\mathrm{A}}$ are proportional to the difference between $\left(\lambda-\mathrm{V}_{\mathrm{A}}\right)$ and $\left(\lambda-\mathrm{V}_{\mathrm{X}}\right)$, where $\lambda$ is the asymptote of conditioning supported by the reinforcer used on that trial,
$\mathrm{V}_{\mathrm{A}}$ is the current associative strength of $\mathrm{A}$, and $V_{X}$ is the current associative strength of all other stimuli present on that trial. Increases in $\alpha_{A}$ occur if $\left(\lambda-V_{A}\right)<\left(\lambda-V_{\gamma}\right)$, and $\lambda_{A}$ decreases if $\left(\lambda-V_{A}\right)>\left(\lambda-V_{X}\right)$.

Overshadowing is predicted to the extent that the presence of a second stimulus, B, either causes a decrease in $\alpha_{\mathrm{A}}$ or prevents $\alpha_{\mathrm{A}}$ from increasing from an initially low value. If $B$ is much more salient than $A, V_{B}$ will increase faster than $V_{A}$, and $\alpha_{A}$ will therefore decline. The presence of $A$, however, cannot cause any decline in $\alpha_{B}$; moreover, of course, if $\mathrm{B}$ is a salient stimulus, $\alpha_{\mathrm{B}}$ will start from a high initial value and will not neea to increase.

If $A$ and $B$ are equally salient, $V_{A}$ and $V_{B}$ will increase at comparable rates, $\left(\lambda-V_{A}\right)$ and $\left(\lambda-V_{B}\right)$ will remain approximately equal, and on reinforced compound trials neither $\alpha_{\mathrm{A}}$ nor $\alpha_{\mathrm{B}}$ will increase. Where $A$ and $B$ are weak stimuli, therefore, some reciprocal overshadowing will occur, since $\alpha_{A}$ and $\alpha_{B}$ will remain low if both stimuli are present, but each will increase if $A$ and $B$ are conditioned in isolation. Where $\mathbf{A}$ and $\mathbf{B}$ are intense stimuli, however, $\alpha_{\mathrm{A}}$ and $\alpha_{\mathrm{B}}$ will start with high values, and further increases in $\alpha$ will be of negligible importance. In the limiting case, where $\alpha_{\mathrm{A}}=\alpha_{\mathrm{B}}=1.0$, there would be no reciprocal overshadowing at all.

\section{REFERENCES}

Kamin, L. J. Predictability, surprise, attention and conditioning. In B. Campbell \& R. Church (Eds.). Punishment and aversive behavior. New York: Appleton-Century-Crofts, 1969.

Mackintosh, N. J A theory of attention: Variations in the associability of stimuli with reinforcement. Psychological Revie'w, 1975, 82, 274-298. (a)

Mackintosh, N. J. Blocking of conditioned suppression: Role of the first compound trial. Joumal of Experimental Psychology Animal Behavior Processes, 1975. 1. 335-345. (b)

Miles, C. G., \& Jenkins, H. M. Overshadowing in operant conditioning as a function of discriminability. Leaming and Motivation. 1973, 4, 11-27.

Pavlov, I. P. Conditioned retlexes. Oxford: Oxford University Press, 1927

Rescorla, R. A., \& Wagner, A. R. A theory of Pavlovian conditioning: Variations in the effectiveness of reinforcement and nonreinforcement. In A. H. Black \& W. F. Prokasy (Eds.), Classical conditioning II Current research and theory. New York: Appleton-Century-Crofts, 1972.

SchnuR, P. Selective attention: Effect of element preexposure on compound conditioning in rats. Journal of Comparative \& Physiological Psychology. 1971. 76, 123-130.

Sutherland, N. S., \& ANDelman, L. Learning with one and two cues. Psychonomic Science, 1967, 15, 253-254.

Sutherland, N. S., \& Mackintosh, N. J. Mechanisms of animal discrimination learning. New York: Academic Press. 1971.

(Received for publication June 10, 1975; revision accepted November 12, 1975.) 